\title{
The Research of Psychological Health Education of the Primary Schools
}

\author{
Ting Cao, Fang Wang \\ Huaihua University, Huaihua, China \\ Email: 763046126@qq.com
}

How to cite this paper: Cao, T. and Wang, F. (2020) The Research of Psychological Health Education of the Primary Schools. Open Access Library Journal, 7: e7015. https://doi.org/10.4236/oalib.1107015

Received: November 18, 2020

Accepted: December 15, 2020

Published: December 18, 2020

Copyright $\odot 2020$ by author(s) and Open Access Library Inc.

This work is licensed under the Creative

Commons Attribution International

License (CC BY 4.0).

http://creativecommons.org/licenses/by/4.0/

(c) (i) Open Access

\begin{abstract}
This study studies the current situation of mental health education in 43 primary schools in Huaihua City. The results show that the mental health education in Huaihua primary schools has been greatly developed in recent years, but there are still some problems: the teachers of mental health education are weak; some schools do not pay enough attention to mental health education; the funds for mental health education are insufficient, and the development is unbalanced; and the course of mental health education is not enough. There are limited problems in the development of psychological counseling and mental health education activities. In order to further improve the level of mental health education in primary schools in Huaihua City, it is necessary to establish a correct concept of mental health education; to strengthen the construction of teachers to improve the level of mental health education; to strengthen the main position of mental health classroom and enrich the forms of mental health education.
\end{abstract}

\section{Subject Areas}

Psychology

\section{Keywords}

Primary School, Mental Health Education, Mental Health Education Teacher

\section{1. 引言}

小学生的健康成长离不开心理的健康, 时代的快速发展也要求小学生有 着健康的心态进行面对。当前小学心理健康教育开展状况直接影响着小学生 心理健康的发展, 国内许多研究者也对小学心理健康教育进行的情况进行了 研究。例如, 陈丹等(2020)的研究发现青少年心理健康, 问题检出率为 $26.3 \%$, 
主要为学习压力感、强迫、焦虑问题[1]。张柳与荆玉梅(2019)对 316 名黄石 市小学生心理健康状况调查发现, 黄石市小学生的心理健康状况主要存在学 习障碍、情绪障碍、社会适应障碍等问题[2]。王纬虹、杨军(2016)对重庆市 9665 名中小学生的心理健康情况调查发现, 主要存在意志力薄弱、交际能力 缺乏、敏感脆弱等问题 [3]。宁式颖等人(2016)对青少年抑郁现状的研究中发 现青少年的抑有检出率有 $26.5 \%$ 之高[4]。由此可见, 青少年的心理健康教育 不容忽视, 在中小学开展心理健康教育显得尤为重要。

学校相比社会与家庭在心理健康教育上承担着更重要的职责。从 1999 年 教育部发布的文件里正式强调心理健康在中小学的重要性, 要求各地逐步开 始心理健康教育[5]。2020 年教育部对具体如何开展心理健康教育发布了正式 文件[6], 2012 新下发的修订文件进一步凸出了中小学心理健康的重要性, 进 一步规范了进行心理健康教育的根本原则、目标要求、具体内容、方法途径以 及实施办法。各级各地教育主管部门也在教育部职能下, 纷纷发布对应地方的 文件来支持当地中小学的心理健康教育发展。然而纵览全国各省市地方学校的 心理健康教育发展情况发现, 虽然经过这些年的发展心理健康教育逐渐得到重 视, 总体有着较大的发展提升。但是由于经济、政治、文化发展的差异性导致 各地心理健康教育发展之间的差异比较大, 而且在实际开展上存在形式主义的 现象, 未能体现心理健康教育的专业性。直至今日, 各地区的心理健康教育 开展状况是否得到调整仍未可知。故需要细致地根据地方发展了解其心理健 康教育的开展情况, 就当地情况提出有效性建议, 从而促进其发展。

湖南省怀化市位于湖南西部, 属于中国西部地区, 有 13 个县区, 有侗族、 苗族、土家族、瑶族等 46 个少数民族, 人口占 $40 \%$, 怀化市境内山丘重叠, 峰峦起伏, 地形复杂, 是一个多民族聚居的山区城市。怀化市在经济上是欠 发达的中小城市, 人口较多, 少数民族人口较多, 留守子女多, 学生升学压 力大。这让怀化的学生呈现出一定的特殊性。然而, 针对怀化市小学生心理 教育健康状况的调查较少, 并且随着这些年国家对心理健康教育的重视, 各 级各地的中小学心理健康教育有了新的发展形势, 怀化市的小学心理健康教 育发展到底呈现出怎样趋势, 与省内其他地区的相比具体的发展状况如何, 这都不得而知。因此, 有必要对怀化市小学生的心理健康教育状况进行研究, 探讨其心理健康教育开展的情况及其存在的问题, 为怀化市心理健康教育更 好的发展提供依据。

\section{2. 研究方法}

\section{1. 研究对象}

本研究通过分层随机抽样的形式, 分别对怀化市区学校、县城学校、乡 镇农村学校进行问卷调查和访谈, 总共 43 所小学, 其中城镇小学有 21 所, 农村小学 22 所。在 43 所学校中, 共有专兼职的心理健康老师 68 人。总共发 放 68 份问卷, 有效问卷有 68 份, 有效问卷回收率为 $100 \%$ 。

\section{2. 研究工具}

根据教育部有关中小学心理健康教育的要求, 参考郝玲 2016 年编制的 
《小学心理健康教育工作情况调查问卷》, 改编问卷[7]。编写完成后请三位 教龄长达 10 年的心理学专家进行内容进行评估, 专家的评分者信度为 0.91 , 专家一致认为测验的题目能够有效的代表所研究的内容, 内容效度较好。通 过对怀化市某小学 30 名教师的初测修订, 确定正式问卷。问卷内部一致性信 度为 0.92 , Cronbach $\alpha$ 系数为 0.79 。正式问卷总共 25 个项目, 涵盖心理健康 教师师资现状、学校心理健康课程开设现状、学校心理健康活动开展现状、 学校心理辅导室的建设与教师关于心理健康教育的态度等等方面。

\section{3. 研究结果}

\section{1. 心理健康教育师资情况}

从表 1 可以看出, 从事心理健康教育工作的专兼职教师, 在总体数量上 较多有 68 人, 几乎所有学校都配备了 $1-2$ 名心理健康教师, 但是在 68 人中, 专职的心理健康教师也只有区区 8 人, 只有 1 人是心理学相关专业毕业, 有 心理教师资格证或心理咨询师证的教师也非常少。调查中只有 28 名教师具有 一定的心理学专业知识, 其余的 40 名教师均为其他科目的教师或领导兼任心 理健康教师。

\section{2. 教师对心理健康教育的认识状况}

由表 2 可知, $76.47 \%$ 的教师认为小学心理健康教育非常重要, $22.06 \%$ 的 老师认为比较重要, 两个项目人数比例之和为 $98.53 \%$ 。由表 3 可知, $14.71 \%$ 的教师对心理健康教育非常了解, $58.82 \%$ 对心理健康教育比较了解, 两个项 目人数比例之和为 $73.53 \%$ 。由此可知大部分教师都认为小学心理健康教育很 重要, 在不同程度上对心理健康教育的知识都有相应的了解。

表 1. 心理健康教育师资情况

\begin{tabular}{ccc}
\hline 项目 & 人数 & 百分比 \\
\hline 心理健康教师总人数 & 68 & \\
专职心理健康教师 & 8 & $11.76 \%$ \\
专业对口 & 1 & $1.47 \%$ \\
有心理教师资格证 & 10 & $14.7 \%$ \\
有心理咨询师证 & 9 & $13.24 \%$ \\
\hline
\end{tabular}

表 2. 教师对心理健康教育重要性的认识

\begin{tabular}{ccccc}
\hline 回答 & 非常重要 & 比较重要 & 不太重要 & 不重要 \\
\hline 52 & 15 & 1 & 0 \\
$76.47 \%$ & $22.06 \%$ & $1.47 \%$ & $0 \%$ \\
\hline
\end{tabular}


表 3. 教师对心理健康教育的了解情况

\begin{tabular}{|c|c|c|c|c|}
\hline 回答 & 非常了解 & 比较了解 & 不太了解 & 不了解 \\
\hline & 10 & 40 & 15 & 3 \\
\hline & $14.71 \%$ & $58.82 \%$ & $22.06 \%$ & $4.41 \%$ \\
\hline
\end{tabular}

\section{3. 心理健康教育课程开设与心理健康活动开展情况}

在 43 所调查的学校中, 令人惊讶的是规范开设心理健康教育的只有 2 所 学校, 此在大部分心理健康教育课程都安排在小学中低年级, 每周大约 0.5 节。但是由于各种原因, 每学期真正的课时不过三四节, 有时更少。虽然学 生普遍反映喜欢心理健康教育课, 但是能够真正得偿所愿则少之又少。

调查中的所有学校都开展过心理健康教育有关的活动。活动的形式多种 这样, 主要包括, 一是: 开展心理健康教育主题活动, 在活动周或活动月进 行与心理健康相关的主题活动, 比如 “ $5 \cdot 25$ 我爱我” 活动。二是：通过与 学校常规的德育教育结合, 在日常的主题班会活动、校园文化活动、社会实 践活动等等穿插心理健康教育。除此之外, 有特色的学校还融入心理剧、团 体辅导活动等等。但是能够科学有效持续开展的学校较少。

\section{4. 心理辅导室建设与心理辅导工作}

根据调查得知, 有 $67.45 \%$ 的学校已建成心理辅导室, 正在筹建的有 $20.9 \%$, 还没有心理咨询室的学校有 $11.65 \%$ 。有心理辅导室的学校 $69.12 \%$ 的 老师说明心理辅导室并不是专用于心理健康教育, 通常会同时兼顾其他功能, 而且有学校反映心理辅导室仅仅只是隔出一个挂牌的地方, 并不存在专业的 设备资源。

各个学校在开展具体的心理辅导上, 虽然都进行了对学生个体的心理辅 导, 但是学校之间的个体心理辅导的人数上差异较大。有的学校能够平均每 个工作日都能接待 $1-3$ 个学生进行心理辅导, 数量较大; 有的学校整个学年 也只接待了几个学生进行心理辅导。此外, 进行心理辅导的主要成员中, 有 $67.44 \%$ 学校是班主任, $20.93 \%$ 的学校是心理健康教师。

\section{4. 讨论}

总体来说, 怀化市的小学生心理健康教育取得一定成绩。从 2017 年市教 育局就对学校心理健康教育有了明确规定, 每个中小学都必须相应的配备 $1 \sim 2$ 名心理健康教育教师, 而且要求全市的全部中小学在 2022 年都必须完成 心理辅导室的建设工作。这在一定程度上保证了心理健康教育的顺利进行。 但是在于与省内其他发达地区比较上, 仍然存在较大的差距, 具体存在的问 题如下:

1) 本地区的心理健康教育师资力量相对薄弱。虽然表面上小学心理健康 教育专兼职教师的总体人数多, 但是真正的专业的心理健康教育老师相对比 例较低。心理健康教育是一门要求专业性强、内容丰富、操作要求高的学科, 
一般的非专业老师难以完全胜任此项工作。因此要做好心理健康教育工作, 必须投入更多的专业老师，同时对兼职的心理健康老师进行更多的专业培训。 在访谈中了解到不少兼职教师反映由于专业知识的限制, 以及本身的教学行 政工作的压力, 难以给学生以专业的心理辅导。

2) 部分学校对心理健康教育重视不够。在访谈相关兼职心理健康老师 时, 特别是某些兼职的学校领导, 他们认为心理健康教育主要是大城市需要, 小地方的学校学生的心理问题完全可以靠班主任解决, 不需要专门开设心理 健康教育课程和安排专门的心理健康老师。所以调查中发现, 怀化市大部分 小学都没有开设心理健康课程, 除了学生学业任务重之外, 与领导的看法不 无关系。一个学校中, 心理健康教育发展得如何, 往往是和学校重视程度密 切相关。

3）心理健康教育经费不足，且发展不平衡。在访谈中了解， $90 \%$ 以上的 学校是没有心理健康教育专项经费的。纵观全市各个学校, 市县重点学校情 况较好, 普通或者乡镇小学仍面临着资金不足, 心理辅导室建设不完整等问 题。虽然教育部在 2012 的文件里明确要求, 心理辅导室的作用就是学校进行 心理健康教育的专门场地, 主要用于学校教师通过个别辅导、团体辅导等形 式, 帮助学生学会解决在学习中、生活中和成长中遇到的心理健康问题, 从 而排解心理问题。由调查结果可知, 虽然 $50 \%$ 的小学都建有心理辅导室, 但 是因缺乏资源设备等等原因, 使其专业功能使用上仍难以保证。

4) 心理健康教育课程、心理辅导和心理健康教育活动展开有限。

根据调查显示, 大部分怀化市的学校都未能完整系统的展开心理健康教 育课程。通过访谈了解到专业教师的缺乏是阻碍之一。此外, 难以正常进行 的心理健康教育课程的开展, 一方面是与当今小学生学业负担重、升学压力 大有关, 再加上大部分的心理健康教师是有其他任课老师兼任, 难以有效进 行心理健康课程的开设; 另一方面是与心理健康教育的地位有关, 学校领导 关于心理健康教育未能恰当认识、正确认识等等。在心理辅导工作上, 主要 的问题还是教师的专业性与场地资源设备的限制等等。在心理健康教育活动 开展上, 据调查了解到能够科学有效持续开展的学校较少, 主要原因还是学 生学业负担重、教师工作忙碌、学校经费紧张。除此之外, 大部分学校简单 的认为展开心理健康教育的价值不大, 难以出效果, 没有成功的活动案例也 在访谈中被提及。

\section{5. 结论与建议}

根据以上的调查结果得知, 怀化市小学心理健康教育仍存在一些问题, 怀化市应根据当前实际的情况进一步完善小学心理健康教育工作，可以通过 以下建议:

1) 树立正确的心理健康教育理念

心理健康教育是非常重要的素质教育。只有学校重视心理健康教育才能 更好地进行心理健康教育的开展。因此, 广大学校只有正确认识心理健康教 育, 树立恰当的心理健康教育理念, 才能真正重视心理健康教育, 也才能更 
好地实行心理健康教育工作。教育管理部门可以通过讲座培训、论坛沙龙、 参观学习先进典型等方式转变关于心理健康教育的认识, 形成恰当的心理健 康教育理念。除此之外, 心理健康教育不应该只是学校的责任, 家庭教育对 于学生的心理健康成长有着重大深远的影响, 故对家长普及相关的心理健康 教育知识, 转变相关家庭教育的理念有着非常积极重要的意义。所以学校可 以协助家长进行这一工作。学校可以采用组织家长参与心理健康教育讲座的 形式, 通过邀请心理学专家解读学生的心理发展, 帮助家长进一步理解学生 的心理动态, 学习有效的家庭教育方式, 从而到达学生心理健康的目的。

2) 加强师资建设，提高教师心理健康教育水准

心理健康教育教师的专业程度在影响心理健康教育教学效果上占至首要 地位。目前制约怀化市心理健康教育发展的很大问题是心理健康教育教师队 伍缺乏专业出身的教师, 导致整体的专业水平不高, 所以学校首先可以做的 是不断引进专业出身的心理健康教育教师，从而在师资数量与专业技能上提 高心理健康教育水准; 同时鼓励其他教师通过各种形式的学习获得心理健康 教育的专业知识与实操技能，从而全面整体地提高学校的心理健康教育水平。

3）强化心理健康课堂的主要地位，丰富心理健康教育开展形式

心理健康教育教育开展的目的在于能够让全体学生全面深刻地学习心理 健康教育的专业知识, 学会调节心理健康的基本方法, 保证在日常生活中解 决基本的心理问题。故学校应该对心理健康教育引起重视, 确保心理健康教 育能够常规展开，从而达到预防学生产生相关心理问题出现不良结果的目的。 在学生日常的科目学习中渗入心理健康教育, 学生在耳濡目染中获得心理健 康教育知识, 是传播心理健康教育的重要途经之一。然而, 心理健康教育又 有别于其他学科知识的学习, 它不单单是简单地给学生传授相关的心理健康 教育知识, 更重要的是要通过情感上去影响学生的心理, 关注学生的内心想 法、内在主观感受等潜在的东西。所以，心理健康教育的开展不能仅仅限制 在日常的课堂上, 所以更重要的是结合当下学生的心理需要, 通过学生乐于 进行的方式, 通过多种多样的方式进行心理健康教育。所以学校通过日常的 主题班会、社会实践活动、素质拓展活动以及学校的广播宣传、板报宣传、 网络自媒体宣传、心理情景剧、心理影视作品等学生喜闻乐见的方式, 通过 各种丰富多彩的心理健康教育形式, 从而能扩展学生得到心理健康教育的途 径。

\section{基金项目}

本文为湖南省 2019 年学生 “创新训练” 资助项目(编号：S201910548044) 成果。

\section{Conflicts of Interest}

The authors declare no conflicts of interest regarding the publication of this paper.

\section{References}

[1] 陈丹, 权治行, 艾梦瑶, 宗春山, 许建农. 青少年心理健康状况及影响因素 [J]. 中 
国健康心理学杂志, 2020, 28(9): 1402-1409.

[2] 张柳, 荆玉梅. 黄石市 316 名小学生心理健康状况分析及对策研究[J]. 湖北师范 大学学报(哲学社会科学版), 2019, 39(4): 112-116.

[3] 王纬虹, 杨军. 中小学生心理健康现状及其教育对策一一基于重庆市 4 9 年级学 生的调查[J]. 现代中小学教育, 2016, 32(9): 77-81.

[4] 宁式颖, 杨玉赫, 李响, 郑璐, 惠文佳. 青少年抑郁现状及影响因素的调查研究 [J]. 山西医药杂志, 2016, 45(8): 890-892.

[5] 教育部. 关于加强中小学心理健康教育的若干意见[Z]. 人民教育, 1999(13): 1-5.

[6] 教育部. 中小学心理健康教育指导纲要 [Z]. 人民教育, 2002(14): 7-9.

[7] 郝玲. 兰州市城关区小学心理健康教育现状与对策研究[D]: [硕士学位论文]. 兰 州: 西北师范大学, 2016 .

\section{Appendix (Abstract and Keywords in Chinese)}

\section{小学心理健康教育现状调查研究}

摘要: 本研究对怀化市的 43 所小学的心理健康教育发展现状进行研究, 结果显示近年来怀化市小学心理健康教育得到很大的发展, 但仍然存在: 心 理健康教育专业师资力量薄弱; 部分学校对心理健康教育重视不够; 心理健 康教育经费不足, 且发展不平衡; 心理健康教育课程、心理辅导和心理健康 教育活动开展有限的问题。为进一步提升怀化市小学心理健康教育水平, 需 要：建立正确的心理健康教育观念；加强师资建设，提高教师心理健康教育 水平; 加强心理健康课堂的主要地位, 丰富心理健康教育开展形式。

关键词: 小学, 心理健康教育, 心理健康教育教师 